University of Nebraska - Lincoln

DigitalCommons@University of Nebraska - Lincoln

USDA Forest Service / UNL Faculty Publications U.S. Department of Agriculture: Forest Service -National Agroforestry Center

$12-7-2009$

\title{
Incorporating remotely sensed tree canopy cover data into broad scale assessments of wildlife habitat distribution and conservation
}

\author{
Sebastián Martinuzzi \\ University of Idaho, smartinuzzi@vandals.uidaho.edu \\ Lee A. Vierling \\ University of Idaho, leev@uidaho.edu \\ William A. Gould \\ International Institute of Tropical Forestry GIS and Remote Sensing Laboratory,wgould@fs.fed.us \\ Kerri T. Vierling \\ University of Idaho, kerriv@uidaho.edu \\ Andrew T. Hudak \\ Rocky Mountain Research Station, ahudak@fs.fed.us
}

Follow this and additional works at: https://digitalcommons.unl.edu/usdafsfacpub

Martinuzzi, Sebastián; Vierling, Lee A.; Gould, William A.; Vierling, Kerri T.; and Hudak, Andrew T., "Incorporating remotely sensed tree canopy cover data into broad scale assessments of wildlife habitat distribution and conservation" (2009). USDA Forest Service / UNL Faculty Publications. 198.

https://digitalcommons.unl.edu/usdafsfacpub/198

This Article is brought to you for free and open access by the U.S. Department of Agriculture: Forest Service -National Agroforestry Center at DigitalCommons@University of Nebraska - Lincoln. It has been accepted for inclusion in USDA Forest Service / UNL Faculty Publications by an authorized administrator of DigitalCommons@University of Nebraska - Lincoln. 


\title{
Incorporating remotely sensed tree canopy cover data into broad scale assessments of wildlife habitat distribution and conservation
}

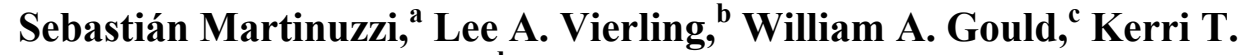 \\ Vierling, ${ }^{\text {d }}$ and Andrew T. Hudak ${ }^{\mathrm{e}}$ \\ ${ }^{a}$ University of Idaho, College of Natural Resources, Geospatial Laboratory for Environmental \\ Dynamics, 975 W. 6th Street, Moscow, Idaho 83844, USA \\ smartinuzzi@vandals.uidaho.edu \\ ${ }^{\mathrm{b}}$ University of Idaho, College of Natural Resources, Geospatial Laboratory for Environmental \\ Dynamics, 975 W. 6th Street, Moscow, Idaho 83844, USA \\ leev@uidaho.edu \\ ${ }^{\mathrm{c}}$ USDA Forest Service, International Institute of Tropical Forestry, Jardín Botánico Sur, 1021 \\ Ceiba Street, Río Piedras, Puerto Rico 00926, USA \\ wgould@fs.fed.us \\ ${ }^{\mathrm{d}}$ University of Idaho, College of Natural Resources, Department of Fish and Wildlife \\ Resources, 975 W. 6th Street, Moscow, Idaho 83844, USA \\ kerriv@uidaho.edu \\ ${ }^{\mathrm{e}}$ USDA Forest Service, Rocky Mountain Research Station, 1221 South Main Street, Moscow, \\ Idaho 83843, USA \\ ahudak@fs.fed.us
}

\begin{abstract}
Remote sensing provides critical information for broad scale assessments of wildlife habitat distribution and conservation. However, such efforts have been typically unable to incorporate information about vegetation structure, a variable important for explaining the distribution of many wildlife species. We evaluated the consequences of incorporating remotely sensed information about horizontal vegetation structure into current assessments of wildlife habitat distribution and conservation. For this, we integrated the new NLCD tree canopy cover product into the US GAP Analysis database, using avian species and the finished Idaho GAP Analysis as a case study. We found: (1) a 15-68\% decrease in the extent of the predicted habitat for avian species associated with specific tree canopy conditions, (2) a marked decrease in the species richness values predicted at the Landsat pixel scale, but not at coarser scales, (3) a modified distribution of biodiversity hotspots, and (4) surprising results in conservation assessment: despite the strong changes in the species predicted habitats, their distribution in relation to the reserves network remained the same. This study highlights the value of area wide vegetation structure data for refined biodiversity and conservation analyses. We discuss further opportunities and limitations for the use of the NLCD data in wildlife habitat studies.
\end{abstract}

Keywords: species distribution model, National Land Cover Database, avian habitat, GAP, horizontal vegetation structure, wildlife conservation.

\section{INTRODUCTION}

Maps describing the distribution of wildlife species are of great importance for biodiversity and conservation assessments. Because remote sensing provides the only means for measuring a range of habitat characteristics across broad scales, scientists commonly use remote sensing data to model species distribution [1-4]. Specifically, because vegetation

This article is a U.S. government work, and is not subject to copyright in the United States. 
characteristics hold great predictive potential for the distribution of wildlife species [5-7], satellite based land cover and vegetation maps are actively used in the modeling process [810]. An example of these efforts is the Gap Analysis Program (GAP) in the United States, a major governmental initiative to model the distribution of wildlife species with remote sensing and associated geospatial datasets, with the main purpose of assessing species conservation for the country [11-13]. Furthermore, the GAP approach has been applied worldwide [14,15].

Although land cover maps are considered adequate to derive species distribution models $[11,16]$ they may not adequately represent the relevant vegetation characteristics for many species' habitats. For example, ecologists have long understood that the presence of certain bird and mammal species can be highly dependent on particular conditions of forest structure, such as those related to tree canopy cover [17,18]. However, land cover and vegetation maps typically do not characterize forest structure. If geospatial data used to support habitat models are not adequate to represent the relevant species-environment relationships, the final distribution maps may not match the observed or expected distributions [19-21], affecting subsequent conservation or biodiversity assessments generated from those maps. The lack of accurate, high spatial resolution biophysical data is considered a major limitation to producing more reliable predictions of species distribution [21]. For broad scale modeling efforts such as those from GAP, detailed information about percent tree canopy cover has been recognized as a major need [22,23].

The recently completed tree canopy cover product of the 2001 National Land Cover Database (NLCD 2001 [24], herein after NLCD_TCC), provides new information about horizontal vegetation structure in the United States, and therefore may serve to fill this important need in wildlife habitat modeling. Originally developed to support land cover requirements for the country, the NLCD_TCC is a nationwide map containing information about the percentage of tree canopy cover at a Landsat spatial resolution (i.e. 30-meter pixel). Evaluating the consequences of incorporating forest structure information into broad scale predictions of species distribution is important given the significance that these maps have for supporting conservation and biodiversity assessments.

In this study, we integrated GAP and NLCD2001data in order to (1) quantify differences in accuracy of GAP predictions of species distribution given the inclusion of tree canopy cover data (i.e. NLCD_TCC), (2) quantify differences in GAP estimates of species distributions and species richness patterns given the inclusion of tree canopy cover data, and (3) quantify differences in the GAP estimates about the species representation within the network of protected lands.

We addressed these questions using a case study comprised of data from the finished Idaho GAP Analysis (ID-GAP, [22]). Idaho contains a diverse array of ecosystems and environmental gradients, and is therefore a good test bed for understanding the general applicability of these questions. From a total of 238 species of birds that occur in Idaho, the ID-GAP identified 37 species that are known to occur under specific tree canopy cover conditions, equivalent to 1 in every 7 birds species present in the state. The authors indicated that the predicted distribution of these 37 species was likely overestimated because the models did not incorporate tree canopy cover constraints [22], but no formal evaluation was made. Our study is an attempt to evaluate the consequences for GAP assessments brought about by the inclusion of novel remote sensing data about vegetation structure. We worked from a GAP perspective because GAP projects are developed across the United States (although the approach has been applied internationally), and because data from GAP are actively used in conservation and planning efforts. However, lessons from this study do not relate solely to GAP and/or the United States; they may also help to assess the value of remote sensing products for advancing biodiversity and conservation assessments regardless of geographic location worldwide. 


\section{MATERIALS AND METHODS}

\subsection{GAP predictions of species distribution and the NLCD2001 tree canopy cover product}

GAP predictive maps of species distribution are developed at a State or regional (i.e. multiState) scale, using a two-step process [25]. First, the species' geographic range is determined by placing the known species occurrences (from GPS points from field surveys, recent museum records, and species lists) in geographic subunits (represented typically by the 635$\mathrm{km}^{2}$ hexagon grid from the Environmental Protection Agency Ecological Mapping and Assessment Program, or EPA-EMAP). About four hundred hexagons are needed, for example, to cover Idaho. Second, information about species-habitat associations (from the scientific literature) is used to identify the suite of (Landsat derived) land cover types, special habitat features (e.g. riparian areas, distance to water bodies, distance to roads) and/or other environmental variables that are suitable for the particular species. The predicted species distribution maps are obtained by intersecting the hexagon based range map with the fine scale habitat requirements. For more information please see the GAP web page $<$ http://GAPanalysis.nbii.gov $>$ ).

The NLCD_TCC product [24] characterizes nationwide vegetation characteristics for the year 2001. The product was developed using Landsat 7 ETM+ satellite imagery in 66 different mapping zones. Within each zone, multiple digital orthophotoquads (DOQ's) were classified into either tree canopy or non-tree canopy areas at $1-\mathrm{m}$ resolution, and these values were then aggregated to the 30 meter scale to determine the percentage of tree canopy [24]. By combining these DOQ derived training data with Landsat spectral data and ancillary information, tree canopy cover predictions were developed using regression tree algorithms. Predictions were applied in areas corresponding to deciduous, coniferous, and mixed forests, woody wetlands, and developed open space. A cross-validation procedure reported an accuracy of about $85 \%$. For more information please see the Multi-Resolution Land Characteristics (MRLC) Consortium website $<$ http://www.mrlc.gov $>$.

\subsection{Study area}

Idaho encompasses about $216,000 \mathrm{~km}^{2}$ in the northwestern United States. Forests represent about $78,000 \mathrm{~km}^{2}(\sim 0 \%$ of the state), are comprised mostly of coniferous species, and occur principally in the mountainous regions of the north and central part of the state (Fig. 1). The southern portion of Idaho is dominated by sagebrush and shrub-steppe vegetation (33\% of the state), and grasslands and agricultural lands (24\%). Riparian vegetation, wetlands, and urban areas cover less than 4\% (Scott et al., 2002b). Protected lands (i.e. reserves) represent about $12 \%$ of the state. About $70 \%$ of the lands in Idaho are public with a majority under US Forest Service management. Excluding riparian areas, forests support the highest wildlife diversity [22]. Forests are subject to a variety of anthropogenic and natural processes that can influence structure and function, such as such as those related to timber extraction, wildfires, blowdowns and landslides.

\subsection{Data}

The data used in this study are of public domain. Data from the ID-GAP were obtained from the GAP server $<$ http://www.GAPanalysis.nbii.gov $>$, including: (1) species geographic range maps, (2) predicted species distribution models and maps, (3) land cover classification map (developed from Landsat imagery from 1996-1998) (see Fig. 1), (4) map of protected areas, (5) ID-GAP Final Report, and (6) metadata. The MRLC Consortium's portal $<$ http://www.mrlc.gov> provided the NLCD_TCC coverage for Idaho (zones 01 and 03) (see 
Fig. 1). We used ArcGIS V9.2 (1999-2006 ESRI Inc.) and ERDAS IMAGINE V9.1 (Leica Geosystems) to process the data.
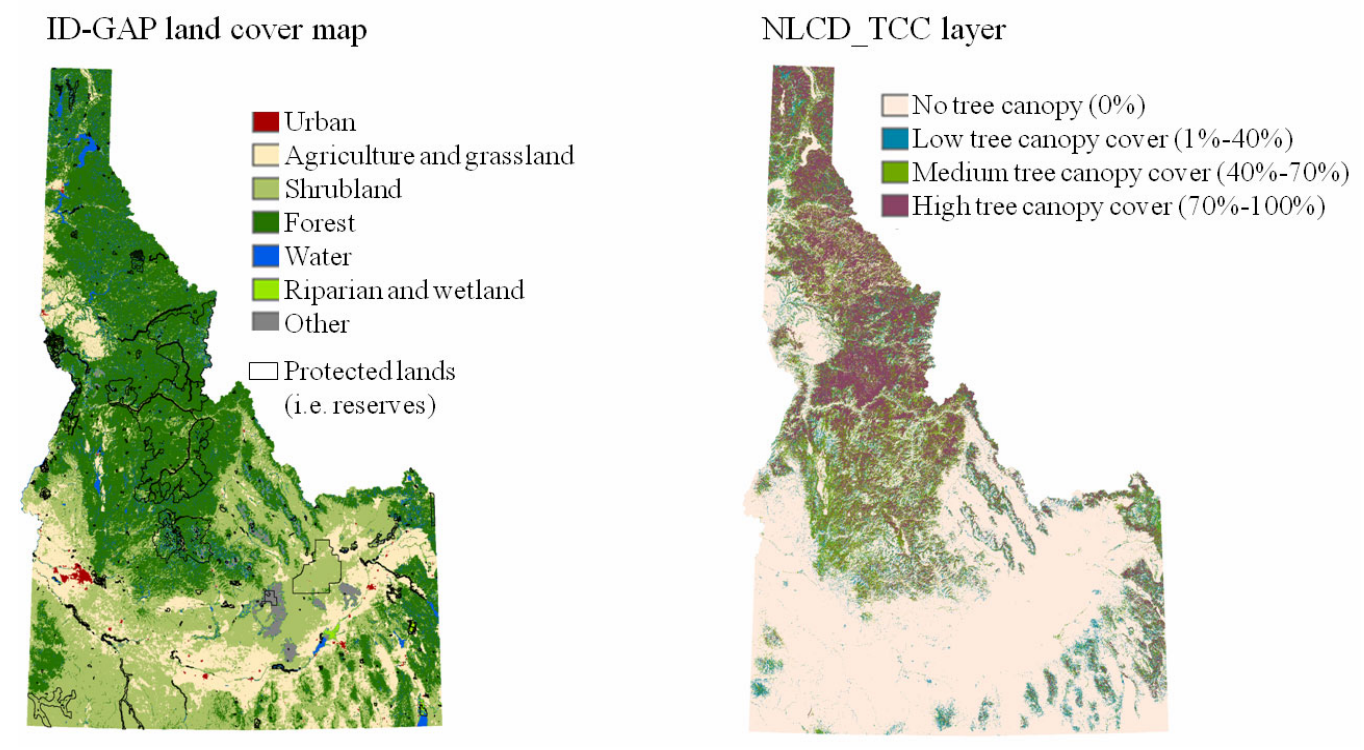

Fig. 1. Simplified land cover map and tree canopy for Idaho.

\subsection{Approach}

The overall approach of this study can be summarized in 3 major steps: (1) identification of the species' tree canopy cover preference, (2) prediction of the species distribution with the new biophysical data (e.g. the NLCD_TCC), and (3) evaluation of species conservation and biodiversity patterns. Steps one and two focused on the 37 bird species identified by the IDGAP as depending on specific conditions on tree canopy cover (and whose habitats have been probably overestimated due to the lack of such data layers). Step three was conducted at two different levels: one that considered the 37 species, and other that included the entire pool of bird species in Idaho $(\mathrm{n}=238)$.

First, we identified the tree canopy preferences for the 37 species of birds using a classification system suggested by the ID-GAP [22], which includes 3 categories: low tree canopy cover $(<=40 \%)$, medium tree canopy cover $(>40 \%$ and $<=70 \%)$, and high tree canopy cover $(>70 \%)$. The ID-GAP provides tree canopy preferences for 20 of the 37 species. We provided information for the other 17 species using (1) internet based scientific reviews, such as The Birds of North America Online <http://bna.birds.cornell.edu/BNA/>, the Point Reyes Bird Observatory (PRBO) Conservation Science $<\mathrm{http}$ ://www.prbo.org $>$, and reports from the US Forest Service Timber Management and Wildlife Interactions Project and Fire Effects Information System database <http://www.fs.fed.us/>; (2) recent studies (e.g. [26.27]), and (3) expert opinion.

Second, we refined the ID-GAP species distribution models by adding the NLCD_TCC data. This is equivalent to subtracting from the original ID-GAP species distribution maps those areas that did not meet the species' habitat preferences in terms of tree canopy cover. As a result, we developed 37 new species distribution maps. We assumed no changes in vegetation between 1998 (the year of the ID-GAP data) and 2001 (the year of the NLCD data).

Third, we compared the original (i.e. ID-GAP) and the refined (i.e. with the NLCD_TCC) predicted distribution maps. We evaluated the changes in terms of total extent of the predicted 
habitat as well as in the proportion of the predicted habitat that occur within the network of protected lands. We created maps of species richness for the 37 species before and after the NLCD_TCC, as well as for the entire pool of species $(n=238)$. For the entire species pool, we used two different spatial scales of analysis: GAP hexagon $\left(635 \mathrm{~km}^{2}\right)$ and Landsat pixel $(900$

$\mathrm{m}^{2}$ ). We compared the new maps of species richness with the original from the ID-GAP in terms of number of species and regional distribution of biodiversity patterns.

\subsection{Accuracy assessment of the new maps of bird species distribution}

We followed the GAP protocol for accuracy assessment [11], using the independent reference data provided by the ID-GAP. GAP uses reference information from locations where high confidence lists of species occurrences have been compiled [25]. Species lists are used because GAP projects develop maps for hundreds of species and over millions of hectares, which makes it impossible to conduct a thorough, field based accuracy assessment of each species map using randomly sampled locations [25]. With this, GAP provides a measure of overall agreement between the predictions and the set of known species locations, and a measure of omission error (failure to predict a species that was present). However, GAP assessments do not provide an estimate of commission errors (prediction of species occurrence in unoccupied area), which is an inherent limitation of GAP [11,25]. In species distribution assessments, commission is more difficult to measure than omission due to the challenges associated with the true and apparent absences in the reference data [28-30]. Although [31] suggested that commission errors can be considered risk-aversive for GAPrelated purposes, information about both commission and omission errors is ultimately important for species distribution maps used in conservation assessment and planning [19,32]. Finally, if five or fewer reference sites are available for assessing the accuracy of a given species, the accuracy assessment for that species is considered not reliable [25].

The independent reference data (i.e. species list) from the ID-GAP encompasses 62 sites. We calculated the \% of correct predictions $(\mathrm{CP} \%)$ and the \% of omissions $(\mathrm{OM} \%)$ for each of the new 37 species maps, and compared the predictions' accuracy (i.e. CP\% and OM\%) before and after the inclusion of tree canopy cover data. Evaluating omission error is important for this study because incorporating tree canopy constraints in the original ID-GAP species-habitat models will likely reduce the extent of the predicted habitats in different amounts.

In addition, we were able to evaluate commission errors. The ID-GAP indicated that the initial distribution of the 37 species was likely overestimated because the models did not incorporate tree canopy cover data [22], but no formal evaluation of the commission error was conducted because of the GAP limitations previously mentioned. We evaluated the magnitude of the initial commission errors by quantifying the changes in the extent of the predicted habitats after adding the tree canopy data. If omission errors are not added after including the tree canopy constraints, any reduction in the predicted habitat will be a consequence of a decrease in original overestimations, and thus, in commission errors. This estimate of commission error is not a result of an accuracy assessment using independent data, but rather is a measure of improvement that arises from interpreting the outputs from the original species-habitat models with the new, more precise ones.

\section{RESULTS}

\subsection{Observed species-habitat associations based on NLCD_TCC and expected distribution patterns}

Five major groups of species emerged after evaluating the species-habitat relationships with respect to land over type (simplified to forest/non-forest) and tree canopy cover (i.e. 
NLCD_TCC) for the 37 avian species (Fig.2). The groups covered a wide range of habitat characteristics; from groups of species that occur both in non-forests and open forests (i.e. forest cover $<40 \%$, group 1), to groups of species that occur only in closed forests (i.e. $>70 \%$ tree canopy cover, group 5). The number of species in each group was variable, with more species in groups associated with forest and non-forest lands (groups 1 and 2) than in groups exclusive from forests (groups 3, 4, and 5). These groupings provided insights about potential patterns of species richness for these 37 species: including (1) open forest pixels were expected to support more species than closed forest pixels, and (2) incorporating tree canopy cover data might produce small changes in open forest pixels, but relatively larger changes in closed forest pixels (see Fig.2).

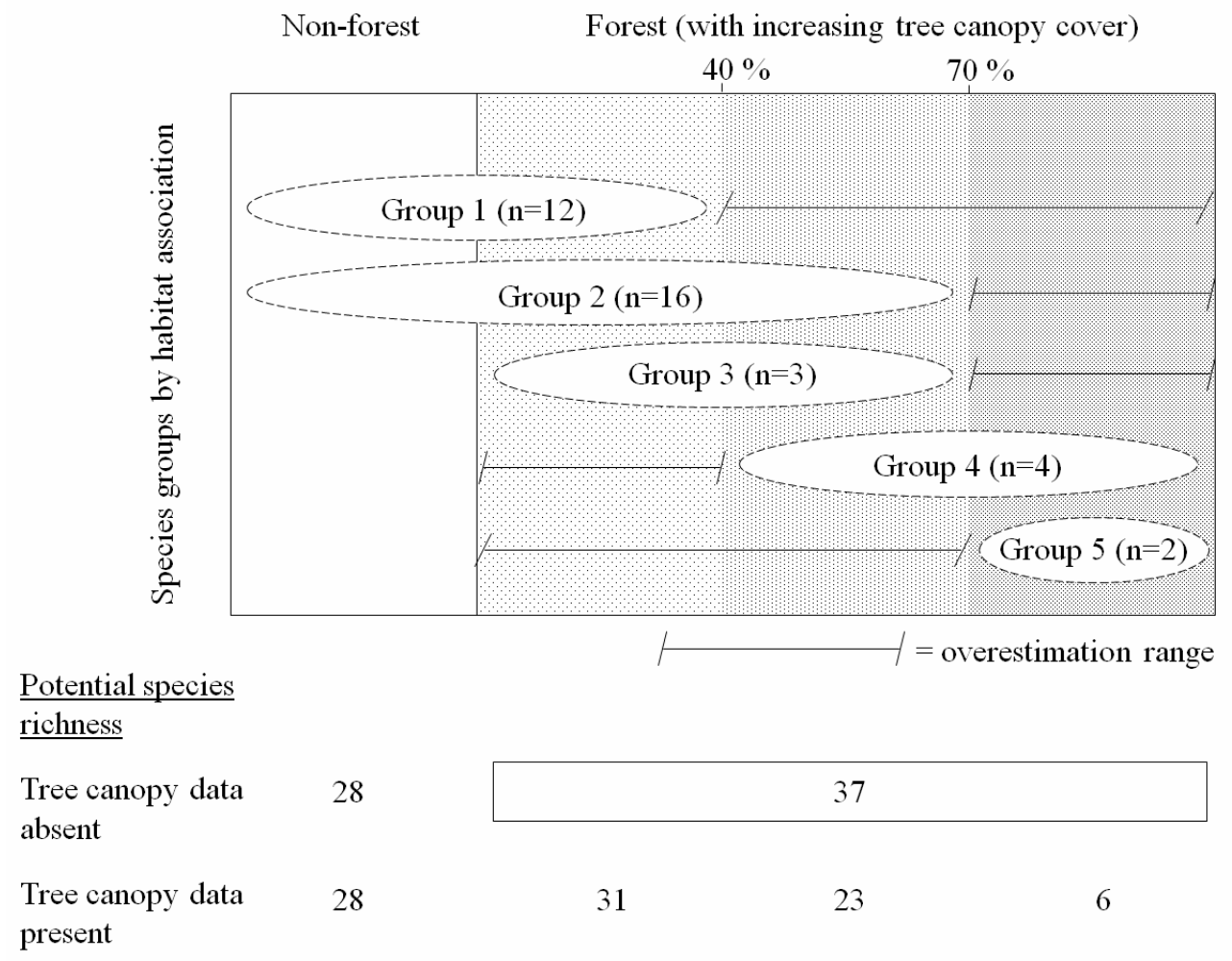

Fig. 2. Distribution of the 37 avian species according to land cover (simplified to forest/non-forest) and tree canopy cover preferences (three classes). Five groups of species were identified based on similar species-habitat relationships. Potential values of maximum species richness for scenarios with and without tree canopy information are also shown. Overestimation range refers to areas (in terms of habitat associations) where the distributions of the species have been overestimated according to the knowledge of the species' natural history.

\subsection{Predicted species distribution incorporating NLCD_TCC data}

The extent of the predicted species distributions decreased markedly after incorporating the tree canopy cover data. For thirty of the thirty-seven bird species, the new predicted habitat was $15 \%$ to $68 \%$ smaller than the original predicted by the ID-GAP (Table 1). For species associated with both non-forested and forested lands (i.e. groups 1 and 2), the decrease in predicted habitat became larger as forest affiliation increased. For example, the smallest 
reductions in habitat $(<=5 \%)$ occurred in six avian species that typically occur in grasslands and/or shrublands but use some forests marginally (e.g. Lark sparrow; Table 1).

Table 1. Predicted habitats before and after the NLCD_TCC. The table includes estimates of total habitat area, and area predicted within protected lands (i.e. reserves). Area unit corresponds to thousands of $\mathrm{km}^{2}$. The species are presented by groups (denoted by the letter "G") similar to Fig. 2.

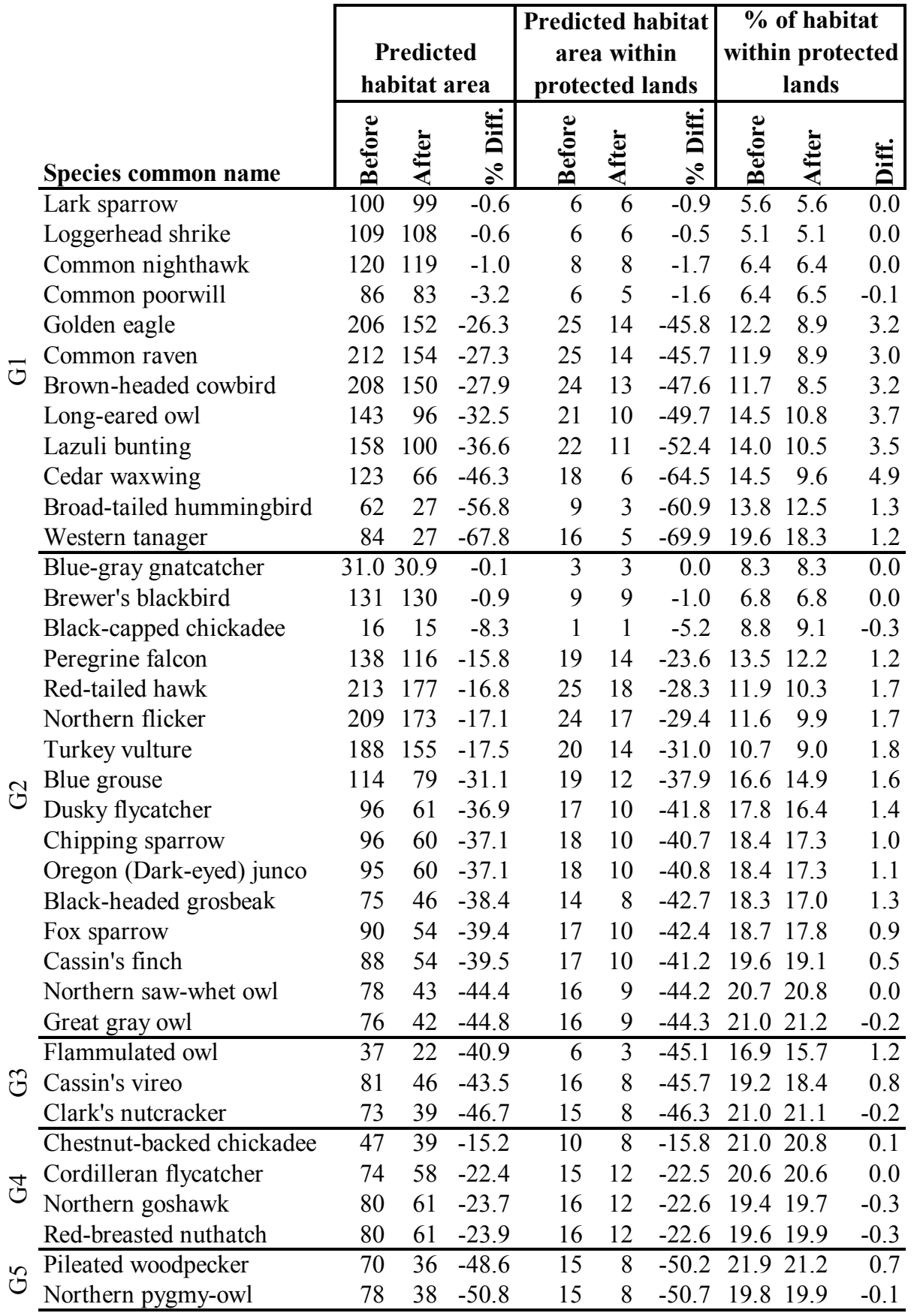

Generalist species such as the Common raven, Golden eagle, or Brown headed cowbird, 
which are known to occur in almost any type of land cover, reported intermediate decreases in habitat size $(15 \%$ to $30 \%)$, while species that utilize forested areas more frequently (yet occasionally use some non-forest lands; e.g. Cedar waxwing) reported the highest changes in habitat size (decreasing between $30 \%$ and $68 \%$ from the original estimates). Finally, for those species that occur exclusively in forests (groups $3,4,5$ ), the changes in the predicted habitat differed depending on the tree canopy preferences. The predicted habitat for species which are thought to occur in forests with tree canopy density $<70 \%$ or $>70 \%$ showed a similar decrease in habitat (between $40 \%$ and $50 \%$ ), while those species that occur in forests with tree canopy density $>40 \%$ showed a smaller habitat reduction (between $15 \%$ and $25 \%$ ).

\subsection{Model evaluation}

The accuracy assessment of the 37 new predictive species distribution models revealed that the incorporation of the tree canopy cover constraints did not result in the addition of omission errors. This was true for all of the species. As a result, neither the percent of correct predictions $(\mathrm{CP} \%)$ nor the percentage of omission $(\mathrm{OM} \%)$ changed after incorporating the tree canopy cover data (Table 2). Because model refinement resulted in habitat reduction without the incorporation of omission errors, the observed changes can be attributed to a decrease in previous commission errors/overestimations. Most of the species models were assessed with 10 to 40 reference sites. Only 3 species were below the ideal minimum of 5 sites (sensu Jennings, 2000), and thus, their accuracy assessment might be unreliable.

Table 2. Accuracy assessment of the initial (i.e. ID-GAP) and refined (i.e. ID-GAP + NLCD_TCC) predicted species distributions, including the number of sites used for evaluation, the $\%$ of correct predictions $(\mathrm{CP} \%)$, and the \% of omissions $(\mathrm{OM} \%)$.

\begin{tabular}{lrrrrr}
\hline & Reference & \multicolumn{2}{c}{ ID-GAP } & \multicolumn{2}{c}{ ID-GAP + NLCD_TCC } \\
\cline { 3 - 7 } Species common name & sites (\#) & CP\% & OM\% & CP\% & OM\% \\
\hline Black-capped chickadee & 25 & 100 & 0 & 100 & 0 \\
Black-headed grosbeak & 18 & 94 & 6 & 94 & 6 \\
Blue grouse & 18 & 100 & 0 & 100 & 0 \\
Blue-gray gnatcatcher & 1 & 0 & 100 & 0 & 100 \\
Brewer's blackbird & 32 & 97 & 3 & 97 & 3 \\
Broad-tailed hummingbird & 8 & 75 & 25 & 75 & 25 \\
Brown-headed cowbird & 31 & 100 & 0 & 100 & 0 \\
Cassin's finch & 14 & 100 & 0 & 100 & 0 \\
Cassin's vireo & 14 & 93 & 7 & 93 & 7 \\
Cedar waxwing & 17 & 100 & 0 & 100 & 0 \\
Chestnut-backed chickadee & 5 & 100 & 0 & 100 & 0 \\
Chipping sparrow & 26 & 92 & 8 & 92 & 8 \\
Clark's nutcracker & 15 & 93 & 7 & 93 & 7 \\
Common nighthawk & 25 & 96 & 4 & 96 & 4 \\
Common poorwill & 9 & 100 & 0 & 100 & 0 \\
Common raven & 29 & 100 & 0 & 100 & 0 \\
Cordilleran flycatcher & 5 & 100 & 0 & 100 & 0 \\
Dusky flycatcher & 13 & 100 & 0 & 100 & 0 \\
Flammulated owl & 4 & 100 & 0 & 100 & 0 \\
Fox sparrow & 10 & 100 & 0 & 100 & 0 \\
Golden eagle & 25 & 100 & 0 & 100 & 0 \\
Great gray owl & 5 & 100 & 0 & 100 & 0
\end{tabular}




\begin{tabular}{lrllll} 
Lark sparrow & 11 & 100 & 0 & 100 & 0 \\
Lazuli bunting & 19 & 100 & 0 & 100 & 0 \\
Loggerhead shrike & 10 & 100 & 0 & 100 & 0 \\
Long-eared owl & 14 & 100 & 0 & 100 & 0 \\
Northern flicker & 40 & 100 & 0 & 100 & 0 \\
Northern goshawk & 15 & 100 & 0 & 100 & 0 \\
Northern pygmy-owl & 11 & 100 & 0 & 100 & 0 \\
Northern saw-whet owl & 14 & 100 & 0 & 100 & 0 \\
Oregon (Dark-eyed) junco & 21 & 100 & 0 & 100 & 0 \\
Peregrine falcon & 2 & 100 & 0 & 100 & 0 \\
Pileated woodpecker & 13 & 100 & 0 & 100 & 0 \\
Red-breasted nuthatch & 16 & 100 & 0 & 100 & 0 \\
Red-tailed hawk & 38 & 100 & 0 & 100 & 0 \\
Turkey vulture & 21 & 100 & 0 & 100 & 0 \\
Western tanager & 20 & 100 & 0 & 100 & 0 \\
\hline
\end{tabular}

\subsection{Species representation within the network of protected lands}

The extent of the species' predicted habitat within protected lands decreased markedly after incorporating the tree canopy cover constraints (Table 1). For most species, these reductions were equivalent to $20 \%$ and $60 \%$ of the original area. Few species from groups 1 and 2 showed changes smaller than 5\%. However, when evaluating the percentage of the predicted habitat within protected lands, we found practically no differences between the original ID-GAP estimates and the new ones incorporating tree canopy cover data $(t=1.48, p$ $=0.15)($ Table 3$)$. In this sense, the changes in the estimates of the species representation within the network of protected lands (i.e. before and after the NLCD_TCC data) did not surpass 5\% (see last column in Table 1).

\subsection{Patterns of species richness after adding NLCD_TCC data}

The species richness values at the pixel scale changed after incorporating tree canopy cover information (Fig. 3). In the map of species richness created with the original predictions for the 37 species (i.e. from the ID-GAP), all the forested pixels appeared to support a high, and relatively constant, number of species (between 25 and 30). In the map that incorporated vegetation structure (i.e. NLCD_TCC), the number of species per pixel was considerably lower (between 8 and 22 for most of the forested pixels) (Fig. 3). The difference between the two maps revealed that the number of species decreased in practically all the forested pixels after incorporating tree canopy constraints, with the largest reductions occurring in areas corresponding to closed forests (the north and center part of the state). Less severe reductions occurred in areas dominated by open forests (e.g. the south-central portion of Idaho).

The pixel based values of species richness including all the birds in Idaho $(n=238)$ also changed after incorporating the 37 new models (Fig. 4 top). Forested pixels showed a decrease in the number of bird species, in proportions that ranged mostly between $5 \%$ and $35 \%$. In the original GAP map, forests were dominated by species richness values between 55 and 80 in the northern and central region, and by slightly lower values in the south. The new map (i.e. after the NLCD_TCC) exhibited lower values of species richness in forests, mostly ranging between 40 and 60 . The changes were higher in areas dominated by closed forests than in areas dominated by moderate density or open forests (see Fig. 4 center). When evaluating the location of species richness hotspots in the forests of Idaho in relationship with the protected lands, the most evident change after adding the tree canopy data was that the 
richest and largest hotspot shifted towards non protected lands, a pattern that differed from the original GAP outputs.

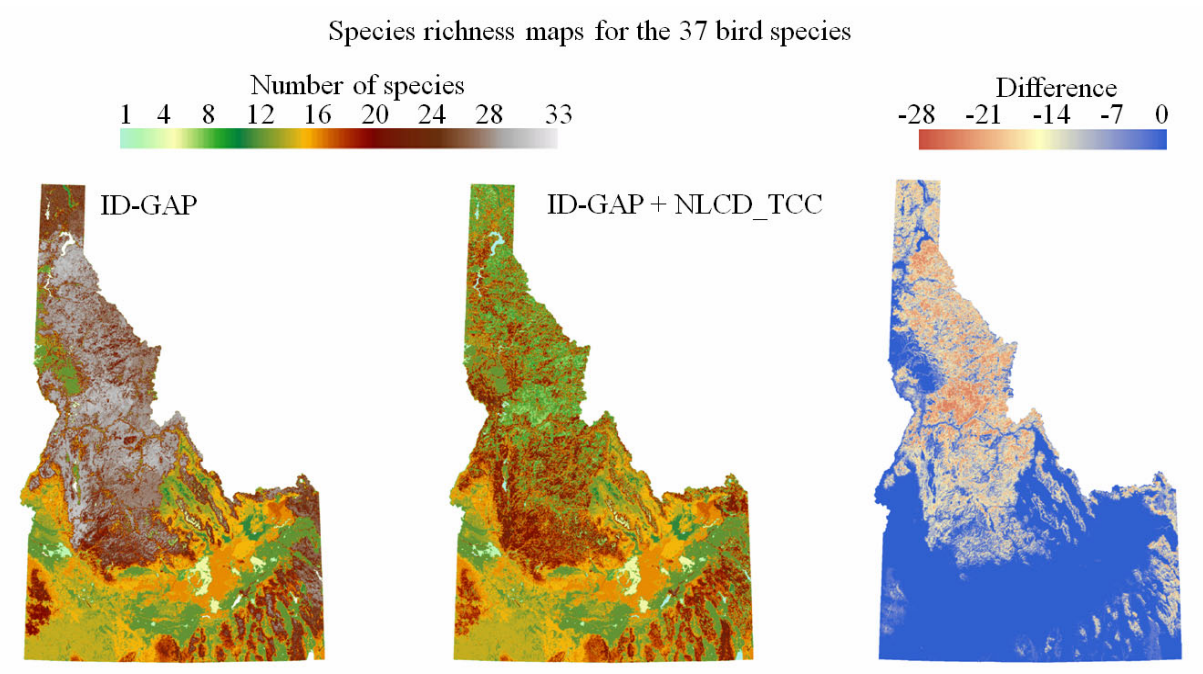

Fig. 3. Pixel based, species richness maps for the 37 avian species, including from the original ID-GAP predicted habitats and from the new ones incorporating the NLCD_TCC. The comparison of species richness between these products is also presented.

At the hexagon scale, the species composition remained unchanged after adding the tree canopy cover data. After refining the predicted distributions of the 37 species with the NLCD_TCC there was still some habitat available for all of the original species listed in the hexagons. Although the predicted habitat per species decreased within the hexagon, this change never resulted in an absence of habitat. The changes observed were a function of the species' preferences and of the characteristics of the dominant vegetation. Hexagons in areas dominated by closed forests experienced higher habitat reductions for species associated with non-forests and open forests (groups 1,2, and 3) and smaller reductions in the habitat for species associated with denser forests (groups 4 and 5), while the opposite was observed in areas of open vegetation (see Fig. 4). Only 6 of the 404 hexagons showed some decrease in the species composition, however these were not the typical $635-\mathrm{km}^{2}$ GAP-hexagons, but rather smaller fractions of those hexagons located along the state border (data not shown).

\section{DISCUSSION AND CONCLUSIONS}

Remote sensing data provide vital information for mapping the distribution of wildlife species, which is a common requisite for assessing species conservation and biodiversity patterns. However, broad scale assessments such as the US GAP Analysis have been conducted using species distribution models that do not incorporate information about vegetation structure, an important variables explaining the distribution of many birds and mammals $[5,6,17,26]$. In this sense, geospatial layers reflecting tree canopy closure has been recognized as a major data need for improving GAP assessments [22,23]. In this study, we evaluated the consequences for broad scale species distribution and conservation assessments brought about by the inclusion of novel remote sensing data about vegetation structure. We integrated the new tree canopy product from the NLCD2001 [24] into GAP species-habitat models, using the state of Idaho as a case study. 

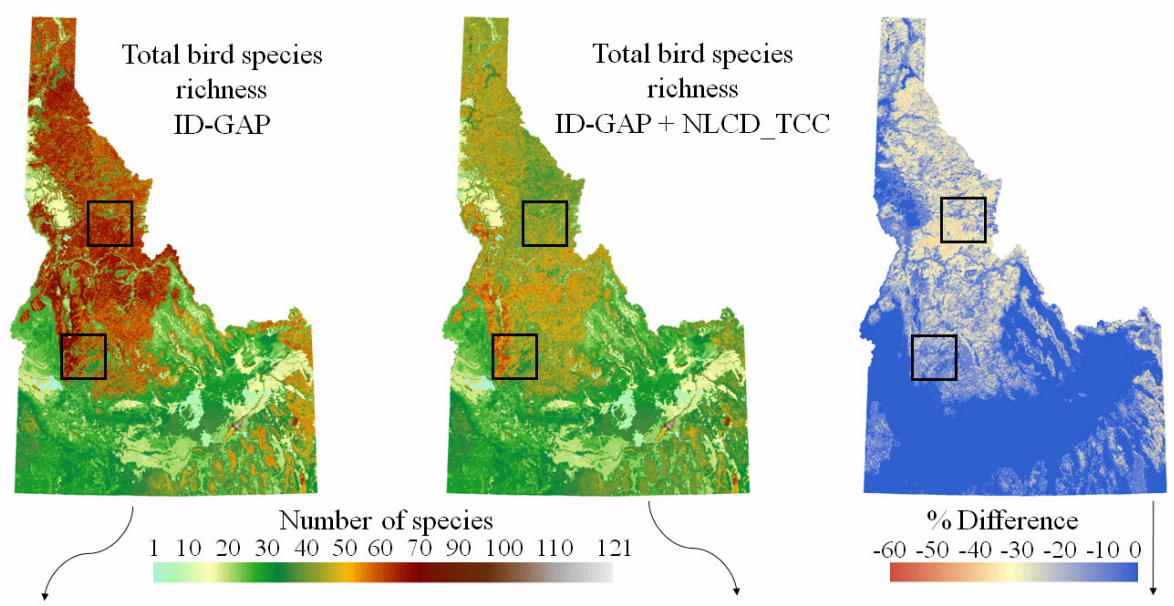

$\%$ Difference
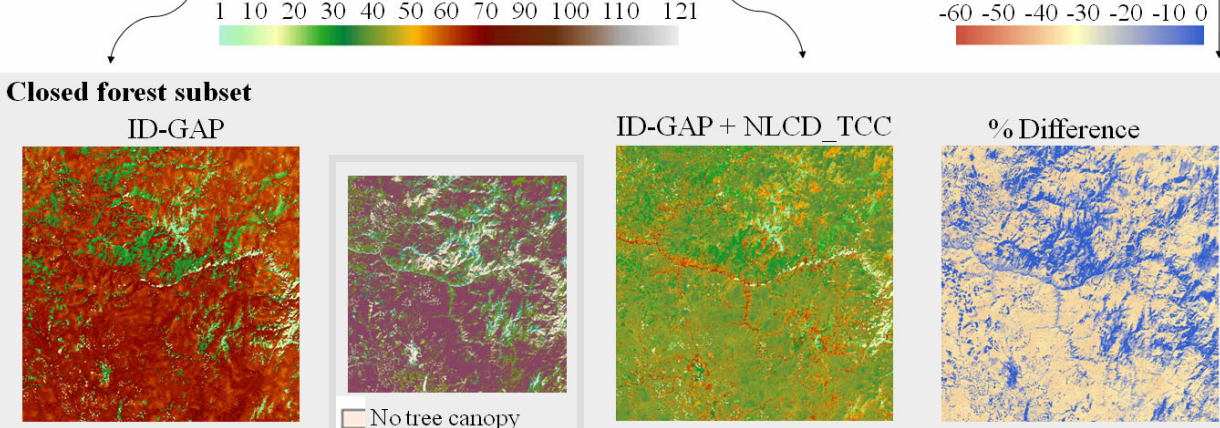

Open forest subset

ID-GAP
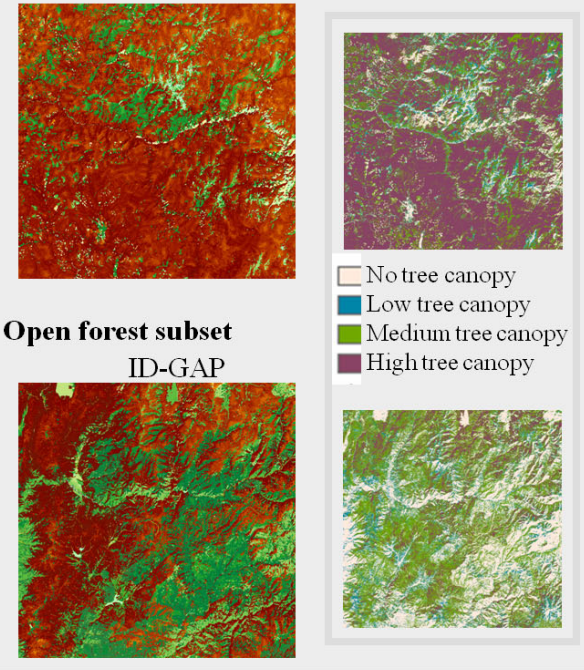

$\square$ Notree canopy

ID-GAP + NLCD TCC

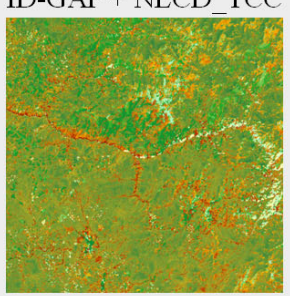

$\%$ Difference

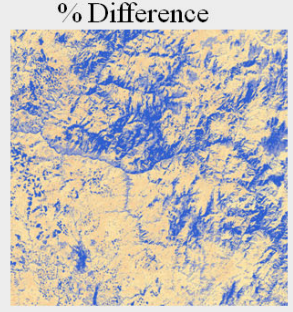

Low tree canopy

Medium tree canopy
High tree canopy
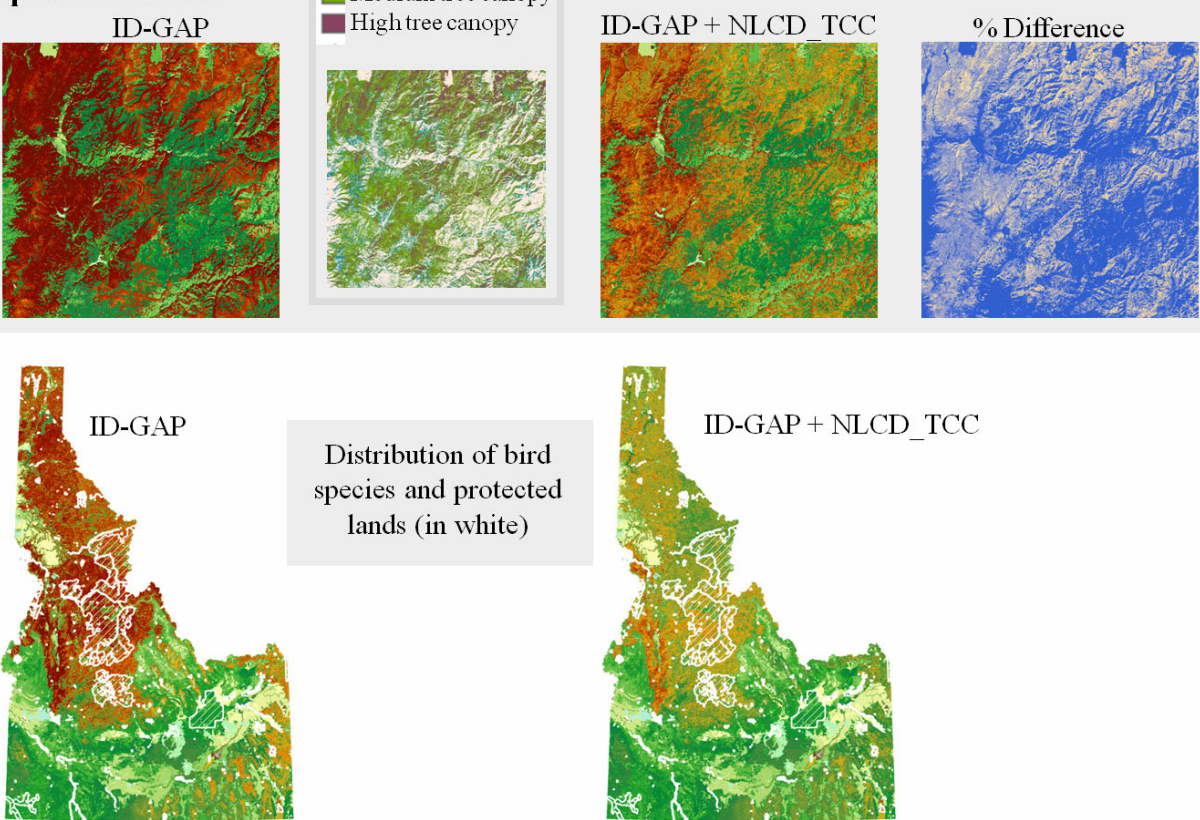

Distribution of bird species and protected lands (in white)

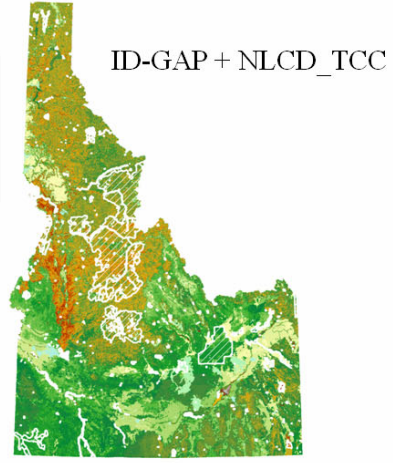

Fig. 4. Pixel based, species richness layers for all the birds in Idaho $(n=238)$, before and after incorporating the NLCD_TCC. Subsets of areas dominated by closed forest and mid-open forest are shown in the center. Patterns of species richness and distribution of protected lands are displayed in the bottom. 
The incorporation of the NLCD_TCC into the GAP habitat assessment protocol resulted in: (1) remarkable changes in the predicted distribution of many avian species, (2) changes in the values of avian species richness at a certain scale, (3) a modified distribution of pixel based biodiversity hotspots in forested areas, and (4) surprising results in conservation assessment. We improved the predicted distribution models of 37 avian species with the NLCD_TCC data, allowing us to represent more precise species-habitat relationships, and reducing previous habitat overestimations without incorporating omission errors. As a result, the assessments of species distribution and conservation based on these refined predictions differed from the original ID-GAP ones (Table 3). Some assessments, however, were not sensitive to model refinement. For example, the most representative GAP measure of conservation, that is, the percentage of the species habitat occurring within the network of protected lands, did not change despite remarkable decreases in the predicted habitat after the NLCD_TCC was added (Table 3).

Table 3. Summary table of the consequences for GAP assessments brought about by the inclusion of broad scale remote sensing data about vegetation structure.

GAP estimates/assessments

Outcome after adding

\section{Predicted Species Distribution Maps}

Area

Omission error

Commission error the NLCD_TCC

Overall accuracy

Species Richness

Pixel-based richness

Hexagon-based richness

Decreased

No change

Decreased

Increased

\section{Species Conservation Assessment}

Predicted habitat within the network of protected lands (in $\mathrm{km}^{2}$ )

Decreased

No change

Predicted habitat within the network of protected lands (in \%)

Decreased

No change

At the scale of this study $\left(216,000 \mathrm{~km}^{2}\right.$, with $78,000 \mathrm{~km}^{2}$ of forests) the addition of geospatial data of vegetation structure represented the difference between a significant habitat overestimation and a more accurate prediction for certain bird species. Modeling the distribution of wildlife species that depend on specific conditions of tree canopy closure in the absence of such data resulted in large overestimation errors. Similar consequences have been observed in other studies with different variables of forest structure For example, [33] noted that giant panda (Ailuropoda melanoleuca) distributions were significantly overestimated without the inclusion of information about understory vegetation. Similarly, the potential distributions of the endangered Delmarva fox squirrel (Sciurus niger cinereus) decreased considerably when adding constraints about forest canopy height [34]. Reductions in habitat size may have consequences for assessing habitat connectivity [33] or for evaluating the species' conservation status based on available habitat. In this sense, our study showed significant habitat reductions for two species listed with the Idaho Department of Fish and Game as in greatest conservation need: the Peregrine falcon (Falco peregrinus anatum) and the Flammulated owl (Otus flammeolus). While our analysis did not evaluate the size and configuration of the new predicted habitats, we speculate that because available habitat became more fragmented after incorporating the NLCD_TCC data, our estimates of habitat reductions are conservative and could be further refined using, for example, concepts of minimum patch size and patch isolation. 
It was surprising to find that, after the large reductions in the predicted distributions for the 37 avian species that resulted from adding the NLCD_TCC data, the estimates of the percentage of the species' habitats occurring within protected lands remained practically the same. The reason for this resides in the similar proportion of tree canopy classes inside and outside protected lands, observed in the forests of Idaho. While some forest types were denser within protected lands (such as Mixed Subalpine Forest or Mesic Forest), others more open (such as Ponderosa pine or Douglas-fir/Lodgepole Pine) and others were relatively similar (such as Douglas-fir or Aspen), the combination of all the forest types canceled such structural differences; as a result, the proportion of low, medium or high tree canopy cover was the same for the forests located inside or outside protected lands (data not shown). The inclusion of NLCD_TCC data in the species habitat modeling process therefore reduced the predicted habitat in a similar fashion inside and outside the reserves, maintaining the original proportions (i.e. by the ID-GAP). In absolute terms, however, the extent of the species predicted habitat (for both inside and outside reserves) decreased markedly after including the NLCD_TCC. Further study is warranted to evaluate these issues in other regions (e.g. broadleaf forests).

For the assessments of species richness, the modification of the predicted distributions of the 37 species produced discernable changes in the pixel based map habitat patterns for all the birds in Idaho $(\mathrm{n}=238)$. The number of bird species predicted to occur in forested pixels decreased as a result of adding tree canopy information. These changes were not homogeneously distributed, and in general, areas dominated by closed forests (mainly in the Rocky Mountains in the north and central part of the state) were more affected than areas dominated by open forests (the southern part). The reason for this is that the majority of the original 37 species are associated with open forests and not with closed forests, and thus, higher overestimations and changes were observed (see Fig. 4) and expected (see Fig. 2) in closed forests. Areas with open forests, including the southern region of the state, exhibited smaller changes. A previous study in an open forest area comparable to the southern part of Idaho (e.g. a mix of shrublands, sparse forests, some closed forests, and grasslands) found that incorporating tree canopy cover in predictive distribution models of avian species did not result in significant changes [16]. However, while model refinement decreased the number of bird species predicted at the pixel level, it did not alter the number of species predicted at the hexagon scale. Differences in responses and patterns of species richness are expected because these products represent information with different spatial resolution (hexagon vs. pixel) [35]. Between these two spatial scales, there will likely exist a new spatial scale at which the consequences of model refinement are still imperceptible for species richness analysis.

Because the reserve network solution from conservation planning efforts is highly sensitive to the quality of the environmental layers and species distribution maps $[32,36]$, further research should evaluate the impacts that novel remote sensing derived data have on the outputs of reserve design analyses. In our study, for example, the new map of bird species richness at the pixel scale revealed the presence of a large biodiversity hotspot located outside of the protected lands (see Fig. 5), a pattern not evident in the original ID-GAP data due to the habitat overestimation problem that occurs in much of the forests. The importance of this hotspot for conservation actions may increase when considering that Idaho is one of the fastest growing states in terms of human population and land development.

The implications of this study, including the potential use of NLCD_TCC data in wildlife habitat assessment, reach beyond bird species. Certain mammals are also known to occur under specific tree canopy cover conditions; for instance the ID-GAP identified nine species whose habitats have been likely overestimated due the lack of tree canopy cover data [22]. The list includes species of major economic importance such as elk (Cervus elaphus) and mule deer (Odocoileus hemionus), and the fisher (Martes pennanti), which is a candidate to be listed under the Endangered Species Act. Considering the relevance of the information about the distribution of these species for supporting conservation and management decisions, 
continue evaluating the incorporation of tree canopy data emerges as an important task for Idaho and beyond.

There is great potential for the immediate application of the NLCD_TCC data for large scale biodiversity mapping and conservation assessments. For instance, the US GAP is developing a second generation of species distribution models for the North Western states, including Oregon, Washington, Idaho, Montana, Wyoming, and California (J. Aycrigg, personal communication). In addition, agencies such as the US Fish and Game are focusing efforts to improve the predicted habitat maps for their species of interest, such as elk and mule deer. Finally, the nationwide development of the State Wildlife Action Plans (SWAP), mandated by the US Congress, might provide an additional framework for species-specific applications. Global assessments looking for tree canopy data, on the other hand, can potentially benefit from the global- $1 \mathrm{~km}$ product developed by the Global Land Cover Facility [37].

The date of the NLCD_TCC data (2001) can be a limitation for analyses seeking to reflect the current (i.e. year 2009) landscape. However, for species that depend on some specific condition of tree canopy cover, the incorporation of the NLCD_TCC may be more relevant than a new land cover that does not reflect vegetation horizontal structure, even if the structural layer is few years old. An additional limitation of the use of these data for wildlife habitat assessment is spatial extent. The product does not provide information about the percent tree canopy cover in areas dominated by grasslands or shrublands, which represent about $35 \%$ of the United States [24]. These areas can contain some tree cover $(<20 \%)$, which represent important features for certain wildlife species. The lack of this type of information when predicting species distribution in rangelands has been identified as a potential cause of omission errors [22].

The avian modeling refinements made possible by incorporating tree canopy cover data in this study highlight the utility of wide area vegetation structure data products for improved species distribution and conservation assessments. Although our study focused on the horizontal component of forest structure, many species select habitat based on 3-dimensional forest canopy structure [5,6]. Information about understory conditions, location of old growth forests, and canopy height have been identified, among others, as important variables for improving the habitat predictions for some wildlife species $[22,23,33,34]$. While obtaining such information from satellite imagery has been difficult, the relatively new airborne lidar (light detection and ranging, or laser altimeter) data may be a potential answer to that problem [38]. The availability of such datasets over regions, nations, or continents will open myriad novel avenues for advancing biodiversity and conservation assessments.

\section{Acknowledgments}

This work was made possible through funding by the US GAP Analysis Program and the USDA Forest Service International Institute of Tropical Forestry (IITF). We thank L. Svancara at the ID-GAP for facilitating the species lists for the accuracy assessment, and A. Haines and H. Jageman for providing information about species-habitat associations for some species. Work at IITF is done in collaboration with the University of Puerto Rico.

\section{References}

[1] H. Nagendra, "Using remote sensing to assess biodiversity," Int. J. Remote Sens. 22, 2377-2400 (2001) [doi: 10.1080/01431160117096].

[2] W. Turner, S. Spector, N. Gardiner, M. Fladeland, E. Sterling, M. Steininger, "Remote sensing for biodiversity science and conservation," Trends Ecol. Evol. 18, 306-313 (2003) [doi:10.1016/S0169-5347(03)00070-3]. 
[3] W. Gillespie, G. M. Foody, D. Rocchini, A. P. Giorgio, S. Saatchi, "Measuring and modelling biodiversity from space," Prog. Phys. Geogr. 32, 203-221 (2008) [doi:10.1177/0309133308093606].

[4] N. Coops, M. A. Wulder, A. M. Pidgeon, V. C. Radeloff, "Bird diversity: a predictable function of satellite-derived estimates of seasonal variation in canopy light absorbance across the United States," J. Biogeogr. (in press) [doi: $10.1111 / \mathrm{j} .1365-2699.2008 .02053 . x]$.

[5] R. H. MacArthur, and J. W. MacArthur, "On bird species diversity," Ecology 42, 594-598 (1961) [doi:10.2307/1932254].

[6] M. L. Cody, Ed., Habitat selection in Birds, Academic Press, Inc., San Diego (1985).

[7] J. M. Scott, P. Heglund, M. Morrison, J. Huafler, M. Raphael, W. Wall, F. Samson, Eds., Predicting species occurrences: issues of accuracy and scale, Island Press, Washington DC (2002).

[8] T. K. Gottschalk, F. Huettmann, M. Ehlers, "Thirty years of analyzing and modeling avian habitat relationships using satellite imagery data: a review," Int. J. Remote Sens. 26, 2631-2656 (2005) [doi:10.1080/01431160512331338041].

[9] G. J. McDermid, S. E. Franklin, E. F. LeDrew, "Remote sensing for large-area habitat mapping," Prog. Phys. Geogr. 29, 449-474 (2005) [doi:10.1191/0309133305pp455ra].

[10] E. Leyequien, C. Verrelst, M. Slot, G. Schaepman-Strub, I. M. A. Heitkönig, A. Skidmore, "Capturing the fugitive: Applying remote sensing to terrestrial animal distribution and diversity," Int. J. Appl. Earth Obs. Geoinf. 9, 1-20 (2007) [doi:10.1016/j.jag.2006.08.002].

[11] J. M. Scott, F. Davis, B. Csuti, R. Noss, B. Butterfield, C. Groves, H. Anderson, S. Caicco, F. D'Erchia, T. C. Edwards Jr., J. Ulliman, R. G. Wright, "GAP Analysis - A geographic approach to protection of biological diversity," Wildlife Monographs 123, 1-41 (1993).

[12] B. R. Noon, D. D. Murphy, S. R. Beissinger, M. L. Shaffer, D. Dellasala, "Conservation planning for the US national Forests: conducting comprehensive biodiversity assessments," Bioscience 53, 1217-1220 (2003) [doi:10.1641/00063568(2003)053[1217:CPFUNF]2.0.CO;2].

[13] J. Maxwell, "Role of GAP data in State Wildlife Plan Development: Opportunities and Lessons Learned," in GAP Analysis Bulletin No 14, J. Maxwell, Ed., pp. 4-11, USGS/BRD/GAP Analysis Program, Moscow ID, USA (2006).

[14] P. M. Fearnside, J. Ferraz, J., "A conservation GAP analysis of Brazil Amazon vegetation," Conserv. Biol. 9, 1134-1147 (1995) [doi:10.1046/j.15231739.1995.9051134.x].

[15] A. S. L. Rodrigues, S. J. Andelman, M. I. Bakar, L. Boitani, T. M. Brooks, R. M. Cowling, L. D. C. Fish-pool, G. A. B. da Fonseca, K. J. Gaston, M. Hoffman, J. S. Long, P. A. Marquet, J. D. Pilgrim, P. L. Pressey, J. Schipper, W. Sechrest, S. N. Stuart, L. G. Underhill, R. W. Waller, M. E. J. Watts, X. Yan, "Global gap analysis: Towards a representative network of protected areas," in Advances in Applied Biodiversity Science, No. 5, Center for Applied Biodiversity Science at Conservation International, Washington DC, USA (2003).

[16] J. Seoane, J. Bustamante, R. Díaz-Delgado, "Are existing vegetation maps adequate to predict bird distributions?," Ecol. Modell. 175, 137-149 (2004) [doi:10.1016/j.ecolmodel.2003.10.011].

[17] M. F. Wilson, "Avian community organization and habitat structure," Ecology 55, 1017-1029 (1974) [doi:10.2307/1940352].

[18]F. C. James, N. O. Wamer, "Relationships between temperate forest bird communities and vegetation structure," Ecology 63, 159-171 (1982) [doi: $10.2307 / 1937041]$. 
[19] A. H. Fielding, J. F. Bell, "A review of methods for the assessment of prediction errors in conservation presence/absence models," Environ. Conserv. 24, 38-49 (1997) [doi:10.1017/S0376892997000088].

[20] T. S. Beutel, R. J. S. Beeton, G. S. Baxter, "Building better wildlife-habitat models," Ecography 22, 219-223 (1999) [doi:10.1111/j.1600-0587.1999.tb00471.x].

[21] A. Guisan, N. E. Zimmerman, "Predictive habitat distribution models in ecology," Ecol. Modell.135, 147-186 (2000) [doi:10.1016/S0304-3800(00)00354-9].

[22] J. M. Scott, C. R. Peterson, J. W. Karl, E. Strand, L. K. Svancara, N. M. Wright, “ $A$ GAP Analysis of Idaho," Final Report, Idaho Cooperative Fish and Wildlife Research Unit, Moscow, ID, USA (2002).

[23] S. Martinuzzi, L. Vierling, W. Gould, K. Vierling, "Improving the characterization and mapping of wildlife habitats with LiDAR data: measurement priorities for the Inland Northwest, USA," in GAP Analysis Bulletin No 16, J. Maxwell, Ed., USGS/BRD/GAP Analysis Program, Moscow ID, USA (in press).

[24] C. Homer, J. Dewitz, J. Fry, M. Coan, N. Hossain, C. Larson, N. Herold, A. McKerrow, J. N. VanDriel, J. Wickham, "Completion of the 2001 National Land Cover database for the Conterminous United States," Photogramm. Eng. Remote Sens. 73, 337-341 (2007).

[25] M. D. Jennings, M.D., "GAP analysis: concepts, methods, and recent results," Landscape Ecol. 15, 5-20 (2000) [doi:10.1023/A:1008184408300].

[26] A. J. Kroll, J. B. Haufler, "Development and evaluation of habitat suitability models at multiple spatial scales: A case study with the dusky flycatcher," Forest Ecol. Manag. 229, 161-169 (2006) [doi:10.1016/j.foreco.2006.03.026].

[27] R. Sallabanks, J. B. Haufler, C. A. Mehl, "Influence of forest vegetation structure on avian community composition in west-central Idaho," Wildlife Soc. B. 34, 1079-1093 (2006) [doi:10.2193/0091-7648(2006)34[1079:IOFVSO]2.0.CO;2].

[28] W. Krohn, W., "Predicted vertebrate distributions from GAP analysis: Considerations in the design of statewide accuracy assessments," in GAP Analysis: A landscape approach to biodiversity planning, J. M. Scott, T. H. Tear, F. W. Davis, Eds., pp. 147-162, American Society of Photogrammetry and Remote Sensing, Bethesda, Md., USA (1996).

[29] J. W. Karl, N. M. Wright, P. J. Heglund, E. O. Garton, J. M. Scott, R. L. Hutto, "Sensitivity of species habitat relationships models performance to factors of scale," Ecol. Appl. 10, 1690-1705 (2000) [doi:10.1890/10510761(2000)010[1690:SOSHRM]2.0.CO;2].

[30] S. M. Schaefer, W. B. Krohn, "Predicting vertebrate occurrcences from species habitat associations: Improving the interpretation of commission error rates," In Predicting species occurrences: issues of accuracy and scale, J. M. Scott, P. Heglund, M. Morrison, J. Huafler, M. Raphael, W. Wall, F. Samson, Eds., pp. 419427, Island Press, Washington DC, USA (2002).

[31] T. C. Edwards, E. T. Deshler, D. Foster, G. G. Moisen, "Adequacy of wildlife habitat Relation Models for estimating Spatial Distributions of Terrestrial vertebrates," Conserv. Biol.10, 263-270 (1996) [doi:10.1046/j.1523-1739.1996.10010263.x].

[32] C. Rondinini, K. A. Wilson, L. Boitani, H. Grantham, H. P. Possingham, "Tradeoffs of different types of species occurrence data for use in systematic conservation planning," Ecol. Lett. 9, 1136-1145 (2006) [doi:10.1111/j.1461-0248.2006.00970.x].

[33] M. Linderman, S. Beaer, L. An, Y. C. Tan, Z. Y. Ouyang, H. G. Liu, "The effects of understory bamboo or broad-scale estimated of giant panda habitat", Biol. Conserv. 121, 383-390 (2005) [doi:10.1016/j.biocon.2004.05.011].

[34] R. Nelson, C. Keller, M. Ratnaswamy, "Locating and estimating the extent of the Delmarva fox squirrel using airborne Lidar profiler," Remote Sens. Environ. 96, 292301 (2005) [doi:10.1016/j.rse.2005.02.012]. 
[35] A. H. Hurlbert, E. P. White, "Disparity between range map- and survey-based analysis of species richness: pattern, process and implications," Ecol. Lett. 8, 319327 (2005) [doi:10.1111/j.1461-0248.2005.00726.x].

[36] K. A. Wilson, M. I. Westphal, H. P. Possingham, J. Elith, "Sensitivity of conservation planning to different approaches to using predicted species distribution data," Biol. Conserv. 122, 99-112 (2005) [doi:10.1016/j.biocon.2004.07.004].

[37] R. DeFries, M. Hansen, J. R. G. Townshend, A. C. Janetos, T. R. Loveland, "A new global $1 \mathrm{~km}$ data set of percent tree cover derived from remote sensing," Glob. Change Biol. 6, 247-254 (2000) [doi:10.1046/j.1365-2486.2000.00296.x].

[38] K. T. Vierling, L. A. Vierling, W. A. Gould, S. Martinuzzi, R. M. Clawges, "Lidar: shedding new light on habitat characterization and modeling," Front. Ecol. Environ. 2, 90-98 (2008) [doi:10.1890/070001]. 